\title{
RESÍDUOS SÓLIDOS: TEMA DA EDUCAÇÃO AMBIENTAL INSERIDO NO BANCO INTERNACIONAL DE OBJETOS EDUCACIONAIS (BIOE)
}

\author{
Egle Katarinne Souza da Silva, UFCG/CCTA \\ Luislândia Vieira de Figueiredo, UFCG \\ Edilson leite da Silva, UFCG/CFP
}

\begin{abstract}
RESUMO
Com o passar do tempo os problemas ambientais têm se alastrado desenfreadamente, e vários motivos podem ser apontados para esta realidade. No que concerne aos Resíduos Sólidos, perante a uma sociedade consumista, é necessário utilizar a Educação Ambiental como aliada no processo de ensino/aprendizagem para formar cidadãos conscientes de seus direitos e deveres sobre a conservação e preservação dos recursos naturais. Realizou-se esta pesquisa como objetivo de quantificar os Objetos Virtuais de Aprendizagem oferecidos pelo Banco Internacional de Objetos Educacionais que abordam o tema Resíduo Sólido, bem como obter um panorama geral e específico relacionado às áreas de conhecimento desses recursos digitais. Classifica-se como uma pesquisa bibliográfica, estudo de caso, descritiva e quantitativa. Constatou-se que o Banco Internacional de Objetos Educacionais oferece uma quantidade considerável de recursos que abordam os conteúdos referentes aos Resíduos Sólidos, no entanto, estes encontram-se somente nos níveis de Educação Fundamental e Educação Superior. Isto se configura como uma carência e reforça a necessidade do desenvolvimento de recursos digitais sobre este tema para os níveis de ensino, tendo em vista que a Educação Ambiental deve ser trabalhada em todos os níveis de ensino.
\end{abstract}

PALAVRAS-CHAVE: Objetos Virtuais de Aprendizagem; Banco Internacional de Objetos Educacionais; Resíduos Sólidos; Educação Ambiental.

\section{SOLID WASTE: ENVIRONMENTAL EDUCATION ISSUE INSERTED IN THE INTERNATIONAL BANK OF EDUCATIONAL OBJECTS}

\begin{abstract}
Environmental problems have spread uncontrollably over time and various reasons can be pointed out as the cause of this reality. With regard to Solid Waste, in a consumer society, it is necessary to use Environmental Education as an ally in the teaching-learning process, to educate citizens aware of their rights and duties on the conservation and preservation of natural resources. This paper aims to quantify the Virtual Learning Objects available at the International Bank of Educational Objects that deal with Solid Waste, as well as to obtain a general and specific overview related to the areas of knowledge of these digital resources. It is classified as a bibliographic, case study, descriptive and quantitative research. It was verified that the International Bank of Educational Objects offers a considerable amount of resources that deal with the contents related to Solid Waste; however these are only available in the Fundamental Education and Higher Education levels. This is configured as a platform and reinforces the need for the development of digital resources on this topic for levels of education, as environmental education should be taught at all educational levels.
\end{abstract}

KEYWORDS: Virtual Learning Objects; International Bank of Educational Objects; Solid Waste; Environmental Education. 


\title{
RESIDUOS SÓLIDOS: TEMA DE LA EDUCACIÓN AMBIENTAL INTRODUCIDO EN EL BANCO INTERNACIONAL DE OBJETOS EDUCACIONALES (BIOE)
}

\begin{abstract}
RESUMEN
Con el pasar del tiempo los problemas ambientales se han expandido desenfrenadamente, y varios motivos pueden ser apuntados para esta realidad. En lo que concierne a los Residuos Sólidos, ante una sociedad consumista, es necesario utilizar la Educación Ambiental como aliada en el proceso de enseñanza/aprendizaje para formar ciudadanos conscientes de sus derechos y deberes sobre la conservación y preservación de los recursos naturales. Se realizó esta pesquisa como objetivo de cuantificar los Objetos Virtuales de Aprendizaje ofrecidos por el Banco Internacional de Objetos Educacionales que abordan el tema Residuo Sólido, bien como obtener un panorama general y específico relacionado a las áreas de conocimiento de esos recursos digitales. Clasificándose como una pesquisa bibliográfica, estudio de caso, descriptiva y cuantitativa. Constándose que el Banco Internacional de Objetos Educacionales ofrece una cantidad considerable de recursos que abordan los contenidos referentes a los Residuos Sólidos, sin embargo, estos se encuentran solamente en los niveles de Educación Fundamental y Educación Superior. Esto se configura como una carencia y refuerza la necesidad del desenvolvimiento de recursos digitales para abordar este tema en el nivel de enseño medio, teniendo en vista que la Educación Ambiental debe ser trabajada en todos los niveles de enseño.
\end{abstract}

PALABRAS CLAVES: Objetos Virtuales de Aprendizaje; Banco Internacional de Objetos Educacionales; Residuos Sólidos; Educación Ambiental.

\section{INTRODUÇÃO}

Os parâmetros curriculares apontam a exigência da Educação Ambiental em todos os níveis de ensino. De fato, o ambiente escolar se configura um local propício para a construção de uma sociedade mais consciente e responsável pela preservação dos recursos naturais. No entanto, a educação ambiental deve ser iniciada nos primeiros anos de vida da criança, para que a mesma cresça aprendendo a preservar e sobre tudo respeitar o meio ambiente. Dessa forma ao adentrar na escola a mesma já terá algum conhecimento sobre o meio ambiente, sendo este lapidado com o incremento de conceitos, construindo aos poucos uma consciência ambiental.

Na Educação Ambiental devem ser abordados diversos conteúdos, sejam eles em abrangência municipal, estadual, federal ou mundial, podem representar uma situação atual quando se quer manter os alunos bem informados sobre os assuntos abordados na mídia, como também ser conteúdos que informem sobre o futuro do meio ambiente e das catástrofes ambientais que podem ser ocasionadas por consequência das ações humanas inadequadas. 
Outro aspecto a se considerar frente à era tecnológica contemporânea, mas do que ensinar o ponto mais preocupante para os docentes nos dias atuais é a forma de como ensinar, qual a melhor maneira de construir o conhecimento, e quais as metodologias adequadas para atrair à atenção do aluno e o interesse em aprender.

Nesse sentido, as tecnologias digitais podem ser utilizadas em sala de aula como suporte no processo de ensino/aprendizagem. Para isto inicialmente o professor necessita estar preparado para o manuseio adequado destes recursos, pois o que determinará a sua eficiência é a metodologia utilizada. Com a utilização de uma nova ferramenta metodológica o professor deixa de ser o único agente ativo na sala de aula e assume o papel de mediador do conhecimento, dando suporte aos alunos no processo de construção do conhecimento.

Um dos recursos digitais que podem ser empregados em sala de aula como auxiliadores na construção do conhecimento são os Objetos Virtuais de Aprendizagem (OVAs), estes são oferecidos por vários repositórios, em diversos formatos, idiomas, para todas as áreas de conhecimento e níveis de ensino.

Neste contexto, a presente pesquisa objetiva realizar uma análise quantitativa dos Objetos Virtuais de Aprendizagem oferecidos pelo Banco Internacional de Objetos Educacionais (BIOE) que abordam o tema Resíduo Sólido, bem como obter um panorama geral e específico relacionado às áreas de conhecimento em que esses recursos digitais se encontram no banco de dados.

\section{REFERENCIAL TEÓRICO}

Mediante as inúmeras catástrofes ambientais vivenciada na sociedade contemporânea, sendo estas ocasionadas pelo uso inconsciente dos recursos naturais, bem como, pelo consumismo indiscriminado e descarte inadequado dos produtos finais consumidos. Levando-se em consideração os problemas ambientais que atingem toda sociedade, é necessário cada vez mais, fornecer à população em geral, um conhecimento aprofundado, realista e atualizado a respeito da responsabilidade que cada cidadão tem perante a conservação e preservação, formando assim em escala global um conjunto de mudanças de hábitos.

Segundo (UNESCO, 2005, p. 43) “A educação nos habilita como indivíduos e como comunidades a compreendermos a nós mesmos e aos outros e as nossas ligações com um 
meio ambiente social e natural de modo mais amplo". Dessa maneira, entende-se que a educação tem o poder de transformar a realidade tanto de um individuo, como de uma sociedade.

A escola é um ambiente ideal e propicio para abordagem das temáticas de impactos sociais, econômicos e ambientais. No que concerne aos impactos ambientais, a Educação Ambiental estabelece uma relação entre o homem e a natureza, da subsidio ao desenvolvimento da conscientização, conservação, preservação e administração adequada dos recursos naturais.

Além da conservação e preservação dos recursos naturais, a Educação Ambiental pode ser utilizada na abordagem de diversos conteúdos, um destes podem ser os Resíduos Sólidos. É sabido que a destinação inadequada dos Resíduos Sólidos geram graves problemas ao meio ambiente e estes afetam todos os âmbitos da sociedade.

Segundo a Norma Brasileira Registrada (NBR) de $\mathrm{n}^{\mathrm{o}}$ 10.004/2004, Os resíduos sólidos são classificados de acordo com seu estado sólido ou semissólido, que se originam de atividades industriais, domésticas, hospitalares, comerciais, de serviços, de varrições e agrícolas, que são (re) utilizados como matéria prima. Entre tanto, é importante diferenciar a definição de lixo e resíduos sólidos. A palavra lixo é considerada como algo que não pode ser reaproveitado, rotulado como "coisas inúteis", velhas e sem valor, ou seja, qualquer material que não apresente mais utilidade e é descartado pelo homem.

O descarte inadequado dos resíduos sólidos tem se tornado um dos mais graves problemas ambientais e sociais da sociedade contemporânea. Segundo Besenet al. (2010), a gestão e a disposição final inapropriada dos resíduos sólidos provoca impactos sociais como ambientais, tais como: Degradação do solo, comprometimento dos lenções freáticos e mananciais, intensificação de alagamentos devido às enchentes, contribuição para a poluição entre outras.

No Brasil são produzidas toneladas de resíduos sólidos. Segundo ABRELPE (2015), em 2015 foram produzidos 79,9 milhões de toneladas de resíduo sólido Urbano. O descarte final desses resíduos na maioria das vezes é feita de maneira inadequada em muitas cidades brasileiras. A coleta é realizada através de órgãos públicos ou por empresas privadas, onde a deposição final acaba sendo os lixões a céu aberto, que causa grandes danos ao meio ambiente. 
Diante desse cenário, o governo brasileiro em 2 de agosto de 2010 instituiu a Política Nacional de Resíduos sólidos (PNRS), Lei Federal 12.305, que aborda os princípios, objetivos e instrumentos, assim como o gerenciamento de resíduos sólidos (incluído os que são classificados como perigosos), as diretrizes relativas à gestão unificada, do poder público, das responsabilidades dos causadores e aos instrumentos econômicos aplicáveis (BRASIL, 2010).

A última etapa da PNRS refere-se à destinação final dos resíduos, configurando-se como um desafio enorme para as cidades em virtude da grande quantidade de resíduos gerada pelas cidades brasileiras. Como alternativas de disposição final podem ser citadas: vazadouro a céu aberto ou lixões, aterro controlado, aterro sanitário, incineração e compostagem. É importante ressaltar que os lixões é a forma mais imprópria de disposição final de resíduos, devido não possuir nenhum tipo de tratamento ambientalmente correto, prejudicando o solo e trazendo riscos a saúde humana.

A alternativa mais viável para a disposição final é o aterro sanitário, que consiste na compactação dos resíduos sólidos em camadas, onde o solo é impermeabilizado, no qual o chorume é canalizado e tratado, evitando a contaminação dos recursos hídricos subterrâneos. A educação ambiental se torna fundamental nesse contexto, uma vez que a orientação sobre a destinação final apropriada dos resíduos sólidos possibilita adquirir o conhecimento necessário para que seja descartado de forma correta.

Brasil (1999, p. 24) ressalta no Art. $2^{\circ}$ que “A educação ambiental é um componente essencial e permanente da educação nacional, devendo estar presente, de forma articulada, em todos os níveis e modalidades do processo educativo, em caráter formal e não-formal". A educação ambiental no espaço escolar objetiva formar cidadãos capazes de refletir sobre questões ambientais, tornando-os ativos dentro uma sociedade mais consciente. Cabe à escola propiciar estratégias que possibilite a aprendizagem voltada à educação ambiental.

Com o avanço tecnológico do século XXI, a utilização de ferramentas digitais como facilitadoras no processo de ensino aprendizagem no espaço escolar tem propiciado uma aprendizagem mais significativa.

Neste contexto, uma alternativa para trabalhar a temática de resíduos sólidos na educação ambiental é a utilização dos objetos virtuais de aprendizagem, sendo que estes possibilita atrair a atenção do alunado por está enquadrado em um cenário no qual, os jovens 
estão inseridos propiciando assim, tornar o ensino mais atraente e dinâmico. Spinelli (2007, p. 7) define os OVAs como:

um recurso digital reutilizável que auxilia na aprendizagem de algum conceito e, ao mesmo tempo, estimula o desenvolvimento de capacidades pessoais, como por exemplo, imaginação e criatividade. Dessa forma, um objeto virtual de aprendizagem pode tanto contemplar um único conceito quanto englobar todo o corpo de uma teoria. Pode ainda compor um percurso didático, envolvendo um conjunto de atividades, focalizando apenas determinado aspecto do conteúdo envolvido, ou formando, com exclusividade, a metodologia adotada para determinado trabalho.

Os OVAs estão disponibilizados em vários portais que podem ser encontrados na internet como o Laboratório Virtual da USP, a Rede Interativa Virtual de Educação e o Banco Internacional de Objetos Educacionais. O BIOE é o portal mais completo e organizado. Como afirma Silva e Salviano, (2015, p.03) "Neste repositório existem objetos de diferentes países e línguas, permitindo a qualquer professor, de qualquer parte do mundo, acessar, utilizar e submeter os recursos em sua língua materna, publicando as suas produções em um processo colaborativo".

Quanto ao layout do repositório, Silva, Figueiredo e Silva (2016, p. 195) afirmam que:

No BIOE, os OVAs encontram-se divididos por níveis de ensino que compreendem os padrões determinados pela Lei de diretrizes e Bases (LDB), são eles: Educação Infantil, Ensino Fundamental, Ensino Médio, Educação Profissional, Educação Superior e Modalidades de Ensino, sendo esta subdividida em Educação de Jovens e Adultos (EJA) e Educação Escolar Indígena. Para cada nível de ensino existem objetos virtuais de aprendizagem que contemplam seus respectivos componentes curriculares. Para todos os componentes curriculares são disponibilizadas 08 categorias, que são: Animação/Simulação, Áudio, Experimento Prático, Hipertexto, Imagem, Mapa, Software Educacional e Vídeo.

No que concerne aos Resíduos Sólidos, perante a uma sociedade consumista, é necessário utilizar a Educação Ambiental como aliada no processo de ensino/ aprendizagem, com o objetivo de formar cidadãos conscientes de seus direitos e deveres sobre a conservação e preservação dos recursos naturais. A inserção da tecnologia na educação ambiental representa uma alternativa viável, pois os recursos digitais tornam o ambiente escolar dinâmico, possibilitando ao professor um suporte no processo de construção do conhecimento do alunado. 


\section{METODOLOGIA}

Realizou-se esta pesquisa na página do BIOE, disponível no endereço eletrônico: $<$ http://objetoseducacionais2.mec.gov.br/>. Este repositório é organizado de maneira sistemática o que facilita o acesso e a utilização dos recursos digitais disponibilizados. Além do acervo digital dos OVAs em vários formatos é possível visualizar no BIOE, as estatísticas gerais e específicas por cada área e nível de ensino, bem como os downloads e visualização de cada objeto virtual submetido.

Utilizou-se o tema Resíduo Sólido para análise no Banco Internacional de Objetos Educacionais referente à disponibilidade de acesso e ao quantitativo de recursos digitais oferecidos. Posteriormente realizou-se a busca e análise das estatísticas gerais do BIOE e específicas referente ao acesso e disponibilidade dos objetos oferecidos para essa temática.

Quanto aos procedimentos metodológicos classifica-se esta pesquisa como bibliográfica e estudo de caso. O embasamento teórico foi realizado em artigos e periódicos que abordam assuntos pertinentes à temática abordada. Para Lakatos e Marconi (2001), a pesquisa bibliográfica compreende toda bibliografia já publicada em relação ao tema pesquisado, desde publicações avulsas, boletins, jornais, revistas, livros, pesquisas, monografias, teses, etc., com a finalidade de colocar o pesquisador em contato direto com tudo o que já foi escrito sobre determinado assunto.

Por centrar-se na temática Resíduos Sólidos trata-se de um estudo de caso, detalhando minuciosamente todos os pontos importantes do caso estudado no BIOE. Para Prodanov e Freitas (2013, p. 60) "o estudo de caso abrange o estudo intenso e cansativo de um ou poucos objetos de maneira que permita o seu amplo e detalhado conhecimento".

Quanto aos objetivos é uma pesquisa descritiva e referente à abordagem classifica-se como quantitativa, pois os resultados obtidos serão analisados e discutidos de forma numérica. Segundo Gil (1999), as pesquisas descritivas têm como escopo principal a descrição das especialidades de determinada população ou fenômeno, ou o estabelecimento de relações entre variáveis.

Os dados descritivos podem ser abordados tanto quantitativamente como qualitativamente. Segundo Malhotra (2001, p.155), “a pesquisa quantitativa procura quantificar os dados e aplica alguma forma da análise estatística". 


\section{RESULTADOS E DISCUSSÃO}

Ao realizar a busca pelo assunto Resíduo Sólidos de maneira geral o BIOE oferece 81 OVAs, conforme apresenta em síntese o Quadro 1. Percebe-se que é uma quantidade considerável, sendo que estes recursos estão divididos por categorias e em níveis de ensino.

Quadro 1 - Demonstrativo dos Objetos para Resíduos Sólidos no BIOE.

\begin{tabular}{|c|c|c|c|c|}
\hline $\begin{array}{c}\text { Data de } \\
\text { Publicação }\end{array}$ & Tipo de Recurso & Título & Autores & $\begin{array}{l}\text { Tamanho dos } \\
\text { arquivos }\end{array}$ \\
\hline $20 / 09 / 2010$ & Imagem & Resíduos sólidos urbanos & $\begin{array}{l}\text { Serviço Intermunicipalizado de Gestão } \\
\text { de Resíduos do Grande Porto (LIPOR) }\end{array}$ & $226.5 \mathrm{~Kb}$ \\
\hline $28 / 04 / 2010$ & $\begin{array}{l}\text { Aminação/ } \\
\text { simulação }\end{array}$ & $\begin{array}{l}\text { Utilização de resíduos de saneamento como matéria-prima } \\
\text { para substrato para produção vegetal }\end{array}$ & $\begin{array}{l}\text { Programa de Pesquisa em Saneamento } \\
\text { Básico - PROSAB }\end{array}$ & $115.9 \mathrm{~Kb}$ \\
\hline $10 / 05 / 2011$ & Imagem & Planta de incineração de resíduos & $\begin{array}{l}\text { Vilhena, André; Compromisso } \\
\text { Empresarial para Reciclagem (CEMPRE) }\end{array}$ & $39.32 \mathrm{~Kb}$ \\
\hline $25 / 08 / 2009$ & Vídeo & Resíduos Sólidos & Junior, Armando Borges de Castilhos & $36.15 \mathrm{~Kb}$ \\
\hline $26 / 08 / 2009$ & $\begin{array}{l}\text { Software } \\
\text { Educacional }\end{array}$ & $\begin{array}{l}\text { VERDES - Viabilidade Econômica de Reciclagem dos } \\
\text { Resíduos Sólidos }\end{array}$ & $\begin{array}{l}\text { Fiocco, Danilo; Magera, Márcio; Robles, } \\
\text { Diogo }\end{array}$ & $23.75 \mathrm{Mb}$ \\
\hline 06/06/2011 & Vídeo & $\begin{array}{l}\text { El aprovechamiento de residuos sólidos reciclables: } \\
\text { Ganancia económica, ambiental y social - Parte } 3\end{array}$ & $\begin{array}{l}\text { Area Metropolitana del Valle de } \\
\text { Aburra; Perez, Magdalena }\end{array}$ & $7.746 \mathrm{Mb}$ \\
\hline $10 / 05 / 2011$ & Imagem & Co-processamento em cimenteira & $\begin{array}{l}\text { Compromisso Empresarial para } \\
\text { Reciclagem (CEMPRE); Vilhena, André }\end{array}$ & $46.90 \mathrm{~Kb}$ \\
\hline $16 / 02 / 2011$ & Imagem & Pátio de compostagem & $\begin{array}{l}\text { Compromisso Empresarial para } \\
\text { Reciclagem (CEMPRE); Vilhena, André }\end{array}$ & $38.51 \mathrm{~Kb}$ \\
\hline 06/06/2011 & Vídeo & $\begin{array}{l}\text { El aprovechamiento de residuos sólidos reciclables con } \\
\text { participación del reciclador - Parte } 1\end{array}$ & $\begin{array}{l}\text { Area Metropolitana del Valle de Aburra; } \\
\text { Perez, Magdalena }\end{array}$ & $11.66 \mathrm{Mb}$ \\
\hline
\end{tabular}

Fonte: BIOE. Acesso em: 17 de março de 2017.

Ao especificar o nível Ensino Fundamental, conforme apresentado no Quadro 2 o BIOE oferece 67 OVAs para o assunto Resíduos Sólidos, correspondendo a 82,71\% de todos os recursos disponibilizados para esta temática. Estes recursos foram desenvolvidos com inúmeros objetivos que se adequam ao contexto geral da temática abordada. Como exemplo pode-se citar o objeto Gestão Sustentável do Lixo Urbano - Cooperativa, com o objetivo de informar sobre os benefícios da reciclagem de lixo para a sociedade e para o meio ambiente e permitir que o aluno conheça o trabalho dos catadores de lixo e o funcionamento das cooperativas de catadores. Informar sobre os processos de reciclagem de diferentes tipos de materiais, desenvolvido pelo Compromisso Empresarial para Reciclagem (CEMPRE), pode ser acessado no endereço eletrônico:

http://objetoseducacionais2.mec.gov.br/handle/mec/19829. 
Quadro 2- Demonstrativo dos Objetos para Resíduos Sólidos no BIOE - Ensino Fundamental.

\begin{tabular}{|c|c|c|c|c|}
\hline Data de Publicação & Tipo de Recurso & Título & Autores & $\begin{array}{l}\text { Tamanho dos } \\
\text { Arquivos }\end{array}$ \\
\hline $10 / 05 / 2011$ & Imagem & Planta de incineração de residuos & $\begin{array}{l}\text { Vilhena, André; Compromisso Empresarial para } \\
\text { Reciclagem (CEMPRE) }\end{array}$ & $39.32 \mathrm{~Kb}$ \\
\hline $06 / 06 / 2011$ & Vídeo & $\begin{array}{l}\text { El aprovechamiento de residuos sólidos reciclables: Ganancia } \\
\text { económica, ambiental y social-Parte } 3\end{array}$ & $\begin{array}{l}\text { Area Metropolitana del Valle de Aburra; Perez, } \\
\text { Magdalena }\end{array}$ & 7. $746 \mathrm{Mb}$ \\
\hline $16 / 02 / 2011$ & Imagem & Pátio de compostagem & $\begin{array}{l}\text { Compromisso Empresarial para Reciclagem } \\
\text { (CEMPRE); Vilhena, André }\end{array}$ & $38.51 \mathrm{~Kb}$ \\
\hline $10 / 05 / 2011$ & Imagem & Co-processamento em cimenteira & $\begin{array}{l}\text { Compromisso Empresarial para Reciclagem } \\
\text { (CEMPRE); Vilhena, André }\end{array}$ & $46.90 \mathrm{~Kb}$ \\
\hline $29 / 11 / 2011$ & Video & $\begin{array}{l}\text { El aprovechamiento de resíduos sólidos reciclables com } \\
\text { participación del reciclador - Parte } 1\end{array}$ & $\begin{array}{l}\text { Area Metropolitana del Valle de Aburra; Perez, } \\
\text { Magdalena }\end{array}$ & $11.66 \mathrm{Mb}$ \\
\hline $06 / 06 / 2011$ & Vídeo & Minas sem lixões- Parte 1 & Fundação Estadual do Meio Ambiente (FEAM) & $10.27 \mathrm{Mb}$ \\
\hline $20 / 03 / 2011$ & Imagem & Reciclagem de entulho & $\begin{array}{l}\text { Vilhena, André; Compromisso Empresarial para } \\
\text { Reciclagem (CEMPRE) }\end{array}$ & $38.73 \mathrm{~Kb}$ \\
\hline $12 / 05 / 2011$ & Vídeo & $\begin{array}{l}\text { El aprovechamiento de resíduos sólidos reciclables: Ganancia } \\
\text { económica, ambiental y social-Parte } 2\end{array}$ & $\begin{array}{l}\text { Perez, Magdalena; Area Metropolitana del Valle de } \\
\text { Aburra }\end{array}$ & $15.68 \mathrm{Mb}$ \\
\hline $12 / 05 / 2011$ & Vídeo & $\begin{array}{l}\text { El aprovechamiento de residuos sólidos reciclables: Ganancia } \\
\text { económica, ambiental y social-Parte } 1\end{array}$ & $\begin{array}{l}\text { Perez, Magdalena; Area Metropolitana del Valle de } \\
\text { Aburra }\end{array}$ & 10.59.Mb \\
\hline $16 / 02 / 2011$ & Imagem & Compostagem de residuos sólidos urbanos & $\begin{array}{l}\text { Compromisso Empresarial para Reciclagem } \\
\text { (CEMPRE); Vilhena, André }\end{array}$ & $41.91 \mathrm{~Kb}$ \\
\hline $20 / 01 / 2011$ & Imagem & Lixão & $\begin{array}{l}\text { Vilhena, André; Compromisso Empresarial para } \\
\text { Reciclagem (CEMPRE) }\end{array}$ & $51.41 \mathrm{~Kb}$ \\
\hline $29 / 11 / 2011$ & Vídeo & Gestão Sustentável do Lixo Urbano-Cooperativa & $\begin{array}{l}\text { Compromisso Empresarial para Reciclagem } \\
\text { (CEMPRE); Vilhena, André }\end{array}$ & $20.51 \mathrm{Mb}$ \\
\hline 06/06/2011 & Video & Minas sem lixỗes- Parte 3 & Fundação Estadual do Meio Ambiente (FEAM) & $13.40 \mathrm{Mb}$ \\
\hline $30 / 05 / 2011$ & Vídeo & Minas sem lixões- Parte 2 & Fundação Estadual do Meio Ambiente (FEAM) & $9.313 \mathrm{Mb}$ \\
\hline
\end{tabular}

Fonte: BIOE. Acesso em: 17 de março de 2017.

Ao especificar Educação Superior, conforme apresentado no Quadro 3, percebe-se que o BIOE oferece 27 OVAs para o tema Resíduo Sólido. Como exemplo, pode-se citar o objeto Resíduos sólidos urbanos, com o objetivo de permitir que o aluno conheça as alternativas possíveis de reaproveitamento e valorização de resíduos sólidos orgânicos e inorgânicos, bem como os métodos de tratamento e disposição final mais comumente utilizados, desenvolvido pelo Serviço Intermunicipalizado de Gestão de Resíduos do Grande Porto (LIPOR), pode ser acessado no endereço eletrônico: http://objetoseducacionais2.mec.gov.br/handle/mec/15138. 
Quadro 3- Demonstrativo dos Objetos para Resíduos Sólidos no BIOE - Educação Superior.

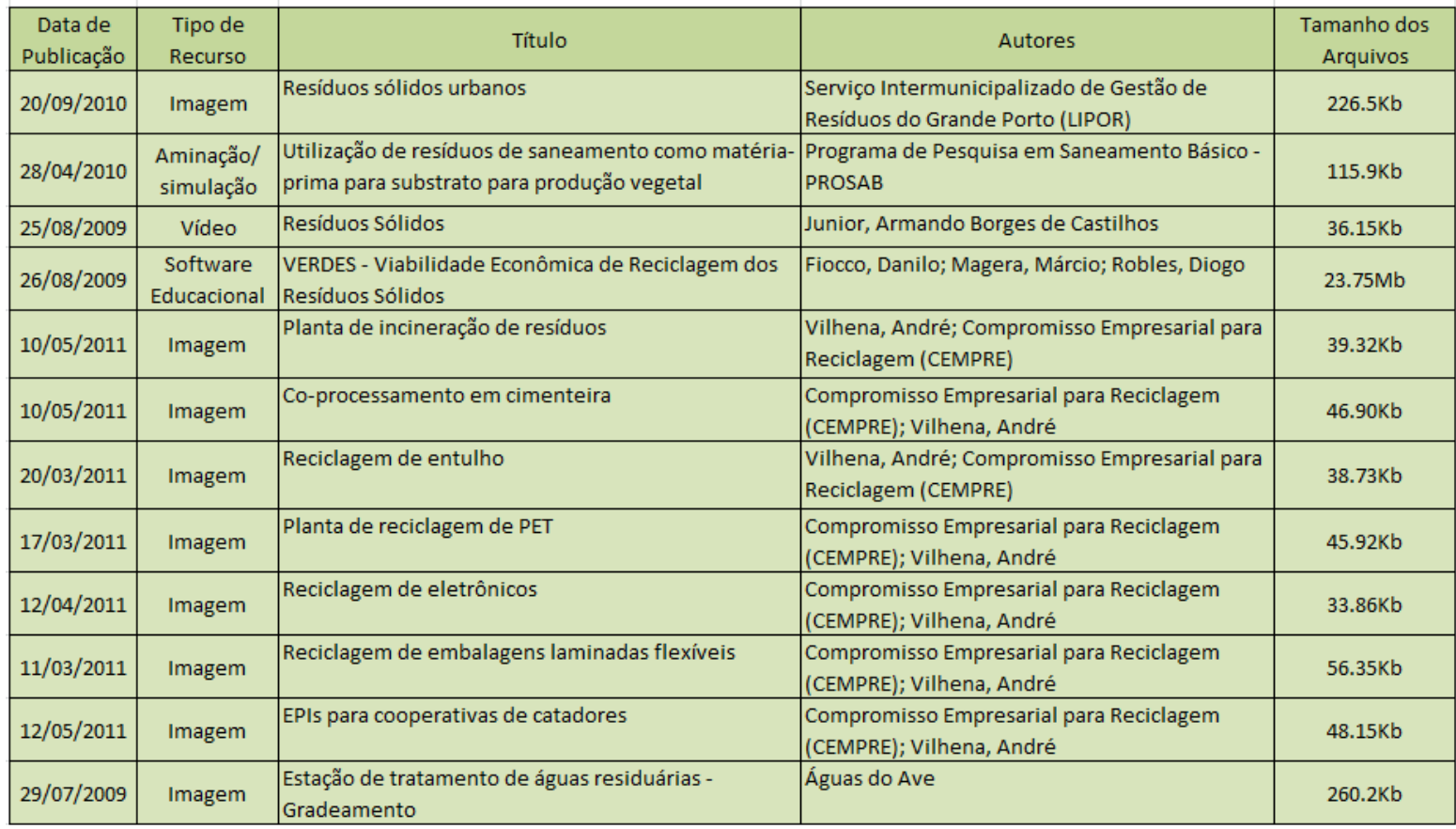

Fonte: BIOE. Acesso em: 17 de março de 2017.

Ao somarmos os objetos disponibilizados para o Ensino Fundamental e Educação Superior obtém-se o valor de 94 OVAs, excedendo assim, 13 objetos referentes ao resultado geral de objetos. Isto ocorre porque dos 81 recursos oferecidos que abordam os Resíduos Sólidos 13 deles são disponibilizados para o Ensino Fundamental e Educação Superior simultaneamente, portanto esses 13 objetos aparecem nos dois níveis de ensino.

No Quadro 4, referente às categorias dos 81 OVAs disponibilizados pelo BIOE para Resíduos Sólidos, observa-se que 43 objetos, correspondendo a 53,1\% do valor total estão na categoria Imagem; 32 recursos são vídeos; 03 Experimentos Práticos; 02 Animação/Simulação e 01 Software Educacional.

Quadro 4- Divisão por Categoria.

\begin{tabular}{|c|c|}
\hline TIPO DE RECURSO & QUANTIDADE \\
\hline IMAGEM & 43 \\
\hline VÍDEO & 32 \\
\hline EXPERIMENTO PRÁTICO & 3 \\
\hline ANIMAÇÃO/SIMULAÇÃO & 2 \\
\hline HIPERTEXTO & 0 \\
\hline MAPAS & 0 \\
\hline ÁUDIO & 0 \\
\hline
\end{tabular}

Fonte: Próprios Autores, 2017. 
Conforme disposição do Quadro 5, dos 67 OVAs disponibilizados para Resíduos Sólidos no Ensino Fundamental 33 estão na categoria Imagem; 31 são Vídeos e 01 Simulador para o componente curricular Meio Ambiente, o BIOE ainda oferece 02 Experimento Práticos para o componente curricular Ciências Naturais.

Os 13 OVAs disponibilizados simultaneamente para o Ensino Fundamental e Educação Superior são Imagens para os componentes Curriculares Meio Ambiente/Engenharias.

Quadro 5 - Divisão por Categoria/Componente Curricular do Ensino Fundamental.

\begin{tabular}{|l|c|c|}
\hline \multicolumn{1}{|c|}{ TIPO DE RECURSO } & QUANTIDADE & $\begin{array}{c}\text { COMPONENTE } \\
\text { CURRICULAR }\end{array}$ \\
\hline IMAGEM & 33 & Meio Ambiente \\
\hline VÍDEO & 31 & Meio Ambiente \\
\hline ANIMAÇÃO/SIMULAÇÃO & 1 & Meio Ambiente \\
\hline EXPERIMENTO PRÁTICO & 2 & Ciências Naturais \\
\hline IMAGEM & 13 & Engenharias/ Meio Ambiente \\
\hline
\end{tabular}

Fonte: Próprios Autores, 2017.

Conforme disposição do Quadro 6, dos 27 OVAs disponibilizados para Resíduos Sólidos no Ensino Superior, 24 estão na categoria de Imagens, sendo 18 para o componente curricular de Engenharias e 06 para Ciências Biológicas e/ou Agrárias; o BIOE ainda oferece 01 Simulador para Engenharias; 01 Vídeo para Ciências e 01 Software Educacional para Biotecnologia.

Quadro 6 - Divisão por Categoria/Componente Curricular do Ensino Superior.

\begin{tabular}{|c|c|c|}
\hline TIPO DE RECURSO & QUANTIDADE & $\begin{array}{c}\text { COMPONENTE } \\
\text { CURRICULAR }\end{array}$ \\
\hline IMAGEM & 18 & Engenharias \\
\hline IMAGEM & 6 & $\begin{array}{c}\text { Ciências } \\
\text { Biológicas/Agrárias }\end{array}$ \\
\hline ANIMAÇÃO/SIMULAÇÃO & 1 & Engenharias \\
\hline VÍDEO & 1 & Ciências \\
\hline SOFTWARE EDUCACIONAL & 1 & Biotecnologia \\
\hline
\end{tabular}

Fonte: Próprios Autores, 2017. 
Na Figura 1 observa-se o quantitativo dos OVAs por categoria, sendo que para Animação/Simulação ao todo o BIOE disponibiliza 5929; Vídeo 4376; Imagem 3631; Áudio 3081; Experimento Prático 1768; Software Educacional 794; Hipertexto 242 e Mapa 21. Totalizando 19.842 objetos virtuais de aprendizagem.

Na Figura 2 observa-se o quantitativo por nível de ensino, destacando-se o Ensino Médio e Educação Superior, respectivamente com 10.289 e 9.206 correspondendo a 92,25\% de todas as categorias.

Figura 1 - Quantitativo por Categoria do BIOE. Figura 2 - Quantitativo por Nível de Ensino do BIOE.

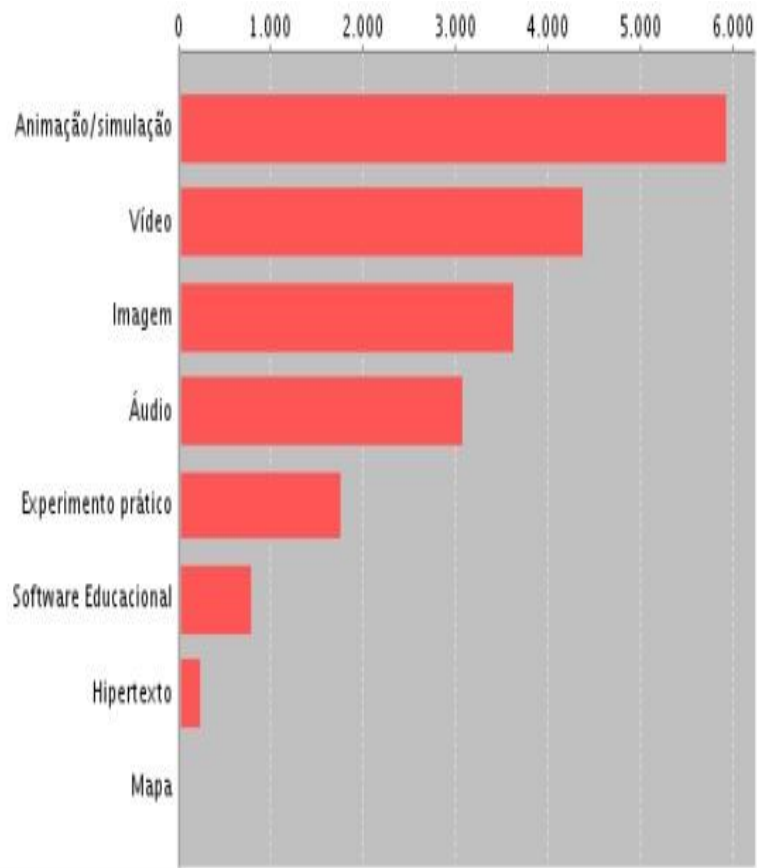

Fonte: BIOE. Acesso em: 14 de abril de 2017.

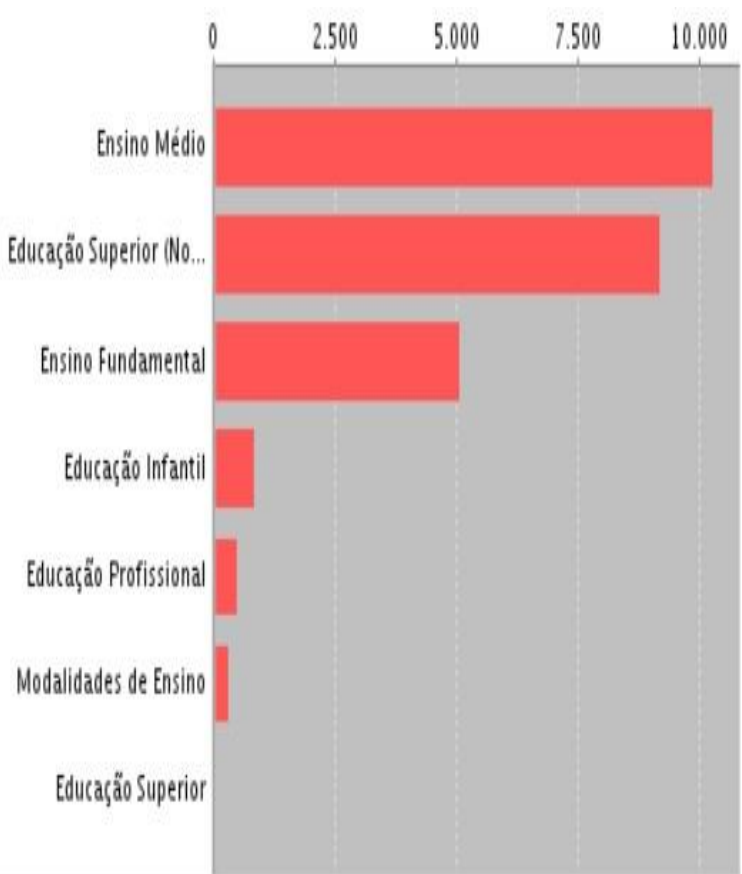

Fonte: BIOE. Acesso em: 14 de abril de 2017.

Quanto aos campos do conhecimento, relacionado ao Meio Ambiente e Ciências Naturais onde se insere a maioria dos recursos digitais que abordam o conteúdo de Resíduos Sólidos, na Figura 3 percebe-se que o BIOE oferece 1971 objetos virtuais de aprendizagem, sendo 1.118 para o Meio Ambiente e 853 para Ciências Naturais.

Em comparação as outras áreas de conhecimento são notórias a diferença quantitativa de objetos, demonstrando assim, a necessidade de desenvolvimento e divulgação de mais recursos digitais no BIOE que abordem assuntos relacionados à Educação Ambiental como os Resíduos Sólidos. Por ser um tema tão importante e que abrange a escala social, econômica e ambiental, torna-se indispensável o incentivo de projetos de pesquisa voltados à 
conscientização e preservação ambiental, tanto nas instituições de ensino superior, como do ensino básico.

Figura 3 - Quantitativo de OE por área do conhecimento.

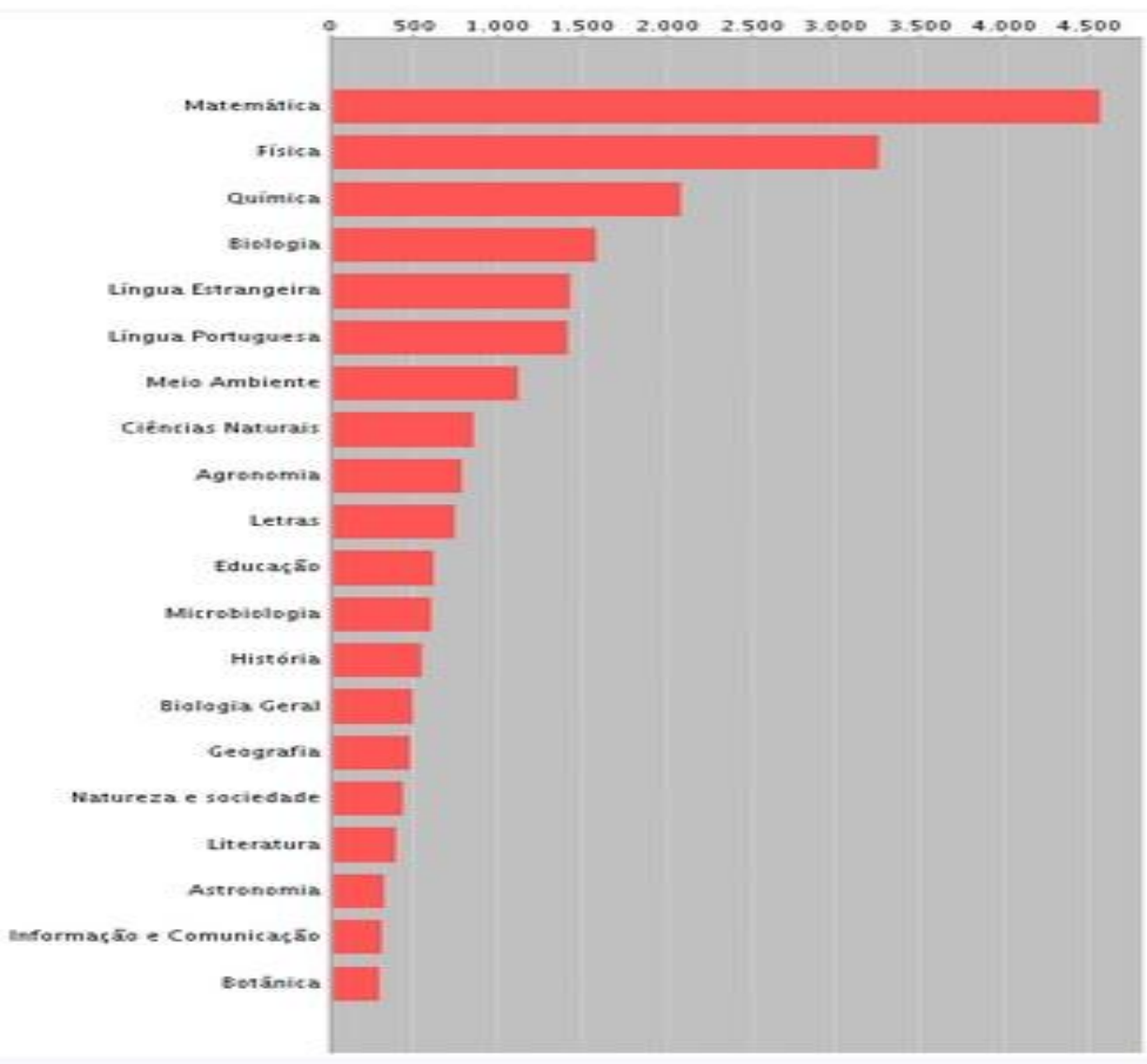

Fonte: BIOE. Acesso em: 14 de abril de 2017.

Atualmente o BIOE é acessado por 159 países, com aproximadamente 892.019 downloads e 2.623 .320 visualizações. Na Figura 4 verifica-se as 10 maiores visualizações por países, sendo Brasil e Estados Unidos recordistas em acessos, seguidos de Japão e Portugal.

Na Figura 5 quanto ao número de downloads em 10 países, seguindo as mesmas estatísticas, observa-se que o Brasil e os Estados Unidos representam os países com maior número de downloads efetuados no BIOE. 
Figura 4- Visualizações por Países do BIOE.

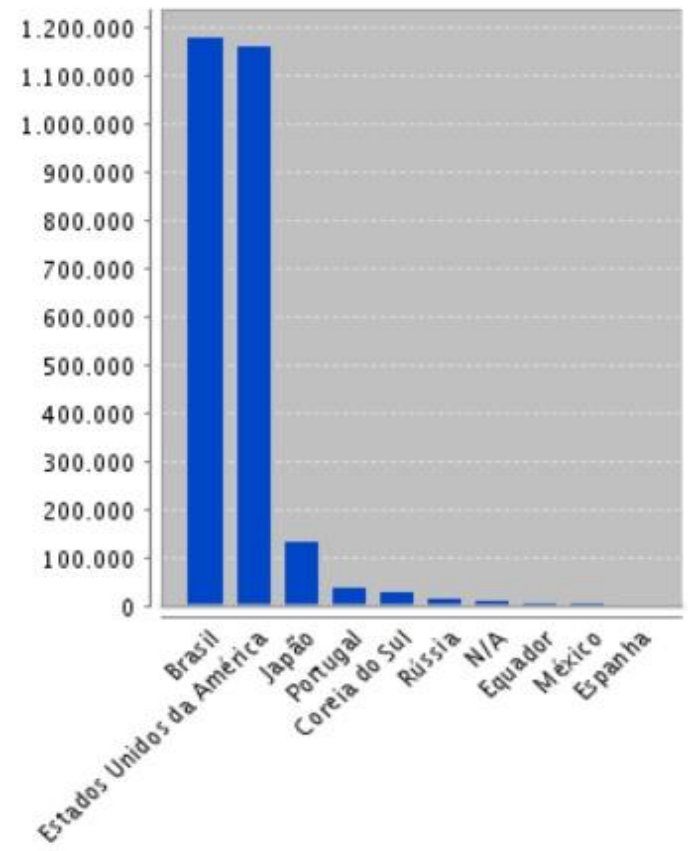

Fonte: BIOE. Acesso em: 14 de abril de 2017.
Figura 5- Downloads por Países do BIOE.

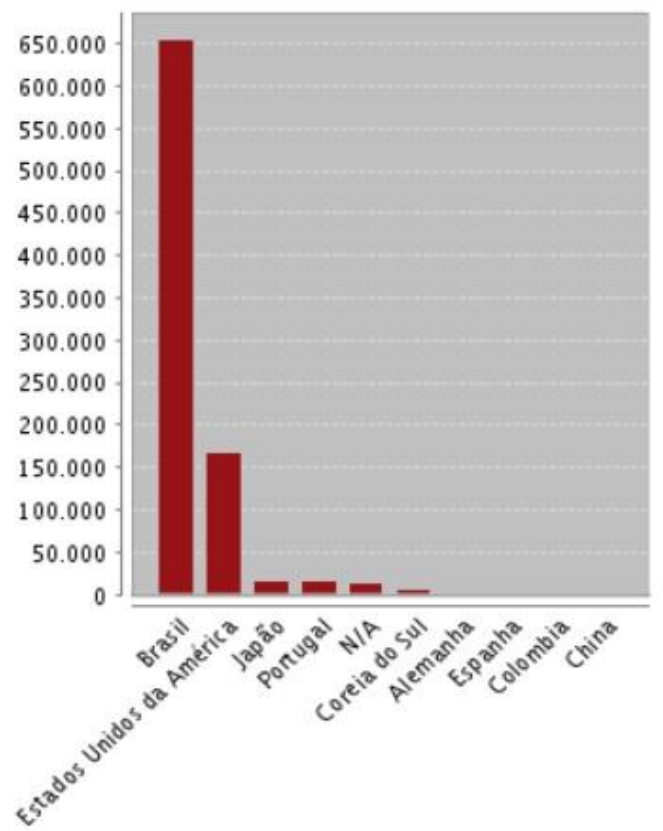

Fonte: BIOE. Acesso em: 14 de abril de 2017.

\section{CONCLUSÕES}

Diante da temática abordada pode-se afirmar que o BIOE disponibiliza uma boa quantidade de recursos digitais para Resíduos Sólidos, isto caracteriza a adequação do repositório com as questões ambientais, sustentabilidade, conscientização populacional e a preocupação de subsidiar os professores enquanto a necessidade da abordagem da Educação Ambiental em salas de aula.

Apesar do número significativo de OVAs oferecido pelo BIOE, é necessário também o incentivo à formação continuada e adequada de professores em todos os níveis de ensino, para que estes se sintam preparados ao incorporar no ambiente escolar recursos digitais, tanto ao trabalhar a Educação Ambiental, bem como em qualquer área do conhecimento.

Referente aos níveis de ensino destaca-se a necessidade de inserção de objetos virtuais de aprendizagem para o ensino infantil, médio, modalidade de ensino e ensino profissionalizante. Levando-se em consideração que a Educação Ambiental deve ser abordada em todos os níveis de ensino e pela importância na abrangência desse conteúdo fica evidente a necessidade da elaboração de OVAs para esses níveis de ensino. 


\section{REFERÊNCIAS BIBLIOGRÁFICAS}

ABNT - Associação Brasileira de Normas Técnicas. ABNT NBR 10004. Resíduos SólidosClassificação, 2004.

ABRELPE - Associação Brasileira de Empresas de Limpeza Pública e Resíduos Especiais. Panorama de Resíduos Sólidos no Brasil- 2015. São Paulo: Abrelpe, 2015. . Disponível em: http://www.abrelpe.org.br/Panorama/panorama2015.pdf, acesso 15 de mai de 2017.

BESEN, G. R. et al. Resíduos sólidos: vulnerabilidades e perspectivas. In: SALDIVA P. et al. Meio ambiente e saúde: o desafio das metrópoles. São Paulo: ExLibris, 2010.

BRASIL. Lei $n$. 12.305, de 02 de agosto de 2010. Institui a Política Nacional de Resíduos Sólidos; altera a Lei ${ }^{\circ}$ 9.605, de 12 de fevereiro de 1998; e dá outras providências. Diário Oficial [da República Federativa do Brasil], Brasília, DF, 2 de agosto de 2010; $189^{\circ}$ da Independência e $122^{\circ}$ da República. Disponível em: http://www.planalto.gov.br/ccivil_03/_ato2007-2010/2010/lei/112305.html Acesso em: 15 mai. 2017.

GIL, A. C. Métodos e técnicas de pesquisa social. 5 ed. São Paulo: Atlas, 1999.

LAKATOS, E. M.; MARCONI, M. A. Fundamentos metodologia científica. 4 ed. São Paulo: Atlas, 2001.

MALHOTRA, N. Pesquisa de marketing. 3 ed. Porto Alegre: Bookman, 2001.

PRODANOV, C. C.; FREITAS, E. C. de. Metodologia do trabalho científico: métodos e técnicas da pesquisa e do trabalho acadêmico. 2 ed. Novo Hamburgo: Freevale, 2013.

SILVA, E. L. da; SALVIANO, A. T. Objetos de aprendizagem para o ensino de matemática. In: COLÓQUIO DE MATEMÁTICA IFCE- Juazeiro do Norte. 12 a 14 de agosto 2015.

SILVA, E. K. S. da; FIGUEIREDO, L. V. de; SILVA, E. L. Banco internacional de objetos educacionais: caracterização dos objetos virtuais de aprendizagem disponibilizados para docência em química analítica. In: Revista de Pesquisa Interdisciplinar, Cajazeiras, v. 1, Ed. Especial, 191 - 201, set/dez. de 2016.

SPINELLI, W. Os objetos virtuais de aprendizagem: ação, criação e conhecimento. 2007. Disponível em: http://rived.mec.gov.br/comousar/textoscomplementares/textoImodulo5.pdf Acesso em: 20 mai. 2016.

UNESCO. Década da Educação das Nações Unidas para um Desenvolvimento Sustentável, 2005-2014: documento final do esquema internacional de implementação. Brasília, 120p. 2005. 